\title{
PAROXYSMAL NOCTURNAL HEMOGLOBINURIA (MEMBRANE DEFECT, PATHOGENESIS, APLASTIC ANEMIA, DIAGNOSIS)
}

\author{
Ladislav Chrobák
}

University Teaching Hospital in Hradec Králové: Department of Clinical Hematology

\begin{abstract}
Summary: Paroxysmal nocturnal hemoglobinuria (PNH) is an acquired clonal disorder in which intravascular hemolysis results from the somatic mutation of the totipotent stem cells causing an intrinsic defect in red cell membrane. PNH cells lack glycosylphosphatidylinositol (GPI) anchored membrane proteins. Of these proteins absence of CD 59 (MIRL - membrane inhibitor of reactive lysis, protectin) and CD 55 (DAF - decay accelerating factor) makes the PNH cells abnormally sensitive to the lytic action of complement. The defect appears to be in the somatic mutation of the X-linked PIG-A (phosphatidylinositolglycan A class) gene which participate in an early step of GPI - anchor synthesis. PNH is characterized by recurrent life threatening venous thromboses and an intimate association with aplastic anemia (AA). It seems that PNH always coexists with bone marrow failure (BMF) (37). The possible explanation may be that some GPI-anchored proteins may be a critical target recognized by immune effector cells. PNH clones not possessing these critical GPI - anchored proteins will survive because they are selectively resistant to the autoimmune assault that eliminates most normal clones. The flow cytometry of erythrocytes using anti-CD 59 and anti-CD 59 and anti-CD 55 of granulocytes has been now introduced as a very sensitive and quantitative method of PNH diagnosis able to detect PNH cells even in normal individuals $(1,54)$. Thus it seems now clear that we must make distinction between the detection of very occasional PNH cells in patients with BMF and PNH as a clinicohematological entity. Unfortunately, we do not know the minimal content of PNH cells required to produce clinical signs of PNH (38).
\end{abstract}

Key words: Paroxysmal nocturnal hemoglobinuria; Membrane defect; Pathogenesis; Aplastic anemia; Spontaneous remissions; Diagnosis

\begin{abstract}
Abbreviations:
AA Aplastic Anemia

AL Acute Leukemia

AMegl Acute Megakaryoblastic Leukemia

AMoL Acute Monocytic Leukemia

BMF Bone Marrow Failure

CD 16 the Fc(receptor III

CD 55 DAF: Decay Accelerating Factor

CD 59 MIRL: Membrane Inhibitor of Reactive Lysis

CML Chronic Myeloid Leukemia

\section{Definition}

Paroxysmal nocturnal hemoglobinuria $(\mathrm{PNH})$ is an acquired chronic anemia in which intravascular hemolysis results from an intrinsic defect in the membrane of red cells that makes them increasingly susceptible to complement. $\mathrm{PNH}$ is often associated with abdominal pain, recurrent lifethreatening venous thrombosis and an intimate association with aplastic anemia (AA).
\end{abstract}

CMMoL Chronic Myelo-monocytic Leukemia

EL Erythroleukemia

GPI Glycosylphosphatidylinositol

MDS Myelodysplastic Syndrom

PIG-A Phosphatidylinositol Glycan-A

PNH Paroxysmal Nocturnal Hemoglobinuria

RAEB Refractory Anemia with Excess of Blasts

RARS Refractory Anemia with Ring Sideroblasts

\section{History}

The first detailed description was given by Strübing in 1882 (66), who described a patient with hemoglobinuria after sleep. Strübing main contribution was to recognize $\mathrm{PNH}$ as different from paroxysmal cold hemoglobinuria triggered by exposure to cold and often associated with syphilis which was not incommon at that time. However, an even earlier report of what may have been PNH was descri- 
bed two centuries earlier in Latin by Johannes Smidt, a Dutch physician, about an ,alderman whose urine turned black when he had attacks of abdominal pain“ (73). The name PNH (Hemoglobinuria paroxysmalis nocturna) was given by Enneking (17). In 1911 A. A. Hijmans van den Berg (71) as first recognized that PNH was a form of hemolytic anemia and expressed the opinion that complement was probably involved. He demonstrated that erythrocytes from a PNH patient were lysed in normal serum acidified with carbon dioxide. The condition became known since a clear basis for laboratory diagnosis was established by Ham (19) in 1937 and independently by Dacie et al. (10) in 1938. They showed that lysis of PNH red cells was caused by a sensitivity to the hemolytic action of complement but was antibody independent. They found that hemolysis could be produce by mild acidification of the serum to $\mathrm{pH} 6.4$, thus activating complement through the alternative pathway. The first publication in this country is by Toušek (70) in 1955. Three other cases were reported by Chrobák et al. in 1957 (29).

\section{Membrane defect}

The previous findings by Ham (19) and Dacie (10) that lysis of PNH cells was caused by an increased sensitivity to the hemolytic action of complement which has been shown to be antibody independent, attracted the interest in an intrinsic defect. Early studies of biochemical abnormalities in PNH red cells revealed that they were deficient in acetylcholinesterase (13), while PNH neutrophils were deficient in alkaline phosphatase (35). This findings are not relevant to complement lysis, but because both of these enzymes are membrane bount, they did point to the membrane defect.

Intravascular hemolysis in $\mathrm{PNH}$ is caused by a clonal red cell population of variable size (52). The cellular abnormality is due to a somatic mutation in one or more totipotent hematopoietic stem cells (52). Cells belonging to this clones have reduced or totally absent expression on their surface of the complement inhibiting proteins (CD 59 and CD 55) as well as of all other proteins attached to the cell membrane by a glycosylphosphatidylinositol (GPI) anchor (55). The fundamental cause of the deficiency is defective synthesis of the GPI at an early step of its biosynthesis - namely the transfer of $\mathrm{N}$-acetylglucosamine to phosphatidylinositol (22). The protein required for this step is encoded by a gene which was called Phosphatidyl Inositol Glycan A or PIG-A, that is somatically mutated in patients with PNH $(5,44,67)$. The PIG-A gene is located at the short arm of the X chromosome (X.p22.1). Some 125 PIG-A mutations are known till now (48). The Nafa et al. (47) have worked about a systemic methodology which allowed to scan for mutations in the entire coding region of the PIG-A gene. By this methodology, they have identified 15 different somatic mutations in 12 patients. The mutation were spread throughout the entire PIG-A-coding region. The predominance was that of frame shift mutations giving rise to clones with a completely nonfunctional PIG-A gene.
Since the PIG-A gene is missing or inactive, GPI-anchor cannot be synthesized in the stem cell-progenitor cells. All patients with PNH who have been studied to date have been shown to harbour defects in the PIG-A gene (2). The mature cells derived from this mutated progenitor cells lack on their surface several proteins. To these proteins belong complement regulatory proteins as decay-accelerating factor (DAF; CD 55 antigen) (51). The lack of DAF does not completely account for the greatly increased sensibility to complement. More important is glycoprotein called membrane inhibitor of reactive lysis (MIRL) (25), protectin (43) or CD 59 antigen. In addition also antibody CD 16 (the $\mathrm{Fc}$ (receptor III) (4) was used in the analysis by flow cytometry on the red cells, granulocytes and platelets (18). Using anti-CD 59, three types of cells could be distinguished; cells with nearly normal expression of GPI-anchored protein (PNH I cells), cells with no detectable expression of GPI-anchored proteins (PNH III cells) and cells with intermediate expression of GPI-anchored proteins (PNH II cells). Deficiency of CD 59 which inhibits late-acting complement complex $\mathrm{C}_{5}-\mathrm{C}_{9}$ activity on the erythrocyte surface accounts for the hemolytic component of the disease. AntiCD 55 did not delineate the erythrocyte population as well as did anti-CD 59. Either anti-CD 55 or anti-CD 59 could be used equally well to analyze granulocytes (72). Anti-CD 16 did not demonstrate cells of partial deficiency (PNH II cells). Platelets could not be used for detailed analysis as the normal and abnormal population were not well distinguished (18). GPI-dependent protein deficient lymphocytes are demonstrable in most if not all patients with PNH (49, $64)$. In most patients, the proportion of abnormal lymphocytes is small, particularly relative to the proportion of abnormal erythrocytes or granulocytes in the some blood. On the other hand, patients who recover from PNH with disappearance of erythrocytes or granulocytes may have a persistent population of GPI-deficient lymphocytes (24). This is though to be due to the longevity of lymphocytes compared with other blood cells.

In some patients more than one independently arisen PIG-A mutation is found, indicating that several different PNH clones may coexist $(38,47)$.

Inherited absence of CD 59 produces phenotype very similar to PNH (75) and therefore acquired CD 59 deficiency offers a good explanation for intravascular hemolysis in PNH.

The fact that GPI-linked proteins are deficient on the membrane belonging to the erythroid, myeloid, megakaryocytic and lymphoid lineage shows that the somatic mutation responsible for PNH phenotype has taken place in a totipotent stem cell, thus qualifying $\mathrm{PNH}$ as a stem cell disorder.

\section{Two population of erythrocytes in PNH}

In PNH unlike other hereditary hemolytic anemias with intravascular cause only a partion of the RBC is affected, 
indicative of a disease having a clonal origin. When erythrocytes from a patient with PNH were subjected to the acid hemolysis test, only a fraction of them was lysed. This finding suggested that the patient's blood contained two populations of erythrocytes - some of them were normal and some abnormal (56). The pathophysiologic relevance of this finding was confirmed by demonstration that these two populations not only differed in vitro, but also to in vivo survival $(12,28,36)$. Testing patients with PNH who were heterozygous for allelic variants of the X-linked GGPD gene, One et al. (52) were indeed able to show that the $\mathrm{RBC}$ population that is hypersensitive to complement only expressed one GGPD allele (52). In this way the clonal origin of PNH was in 1970 first time clearly documented. The clonal origin of PNH was later also confirmed on erythroid colonies grown in vitro (60). Based on two independent criteria (sensitivity to acidified serum and acetylcholinesterase content) dual population of erythroid burst forming units (BFU-E) could be demonstrated in PNH colonies.

\section{The pathogenesis of PNH}

Does a PIG-A mutation in pluripotent hematopoietic stem cell inevitably lead to the development of PNH? The answer to this question lies in the relationship between AA and PNH. The first descriptions of PNH associated with BMF are by Dacie et Gilpin in 1944 (9), by Letman in 1952 (34) and by Dacie et Lewis in 1961 (11). In this country Chrobák et al. (28) reported about 4 patients, with BMF out of 8 patients with PNH. Chrobák and Brabec (27) found in 1965 out of 214 patients collected from the literature leukopenia below 4,0 x 109/1 in 107 (50\%), below 3,0 $\mathrm{x} 10^{9} / 1$ in $\left.6128,5 \%\right)$, below $2,0 \times 10^{9} / 1$ in $17(7,9 \%)$ and below $1,0 \times 10^{9} / 1$ in 3 (14\%) of patients. Thrombocytopenia below $100,0 \times 10^{9} / 1$ was present in 56 patients $(41,8 \%)$. It is probable that many patients with predominant manifestation of in PNH were not diagnosed that time. Dunn et al. (16) found evidence of PNH in 25 of 115 (22\%) patients with AA. Abnormal cells were not detected in patients with constitutional or other forms of bone marrow failure or in renal allograft recipients who had received antithymocyte globuline. According to the hypothesis of Luzzatto (37) PNH always coexist with BMF. Considering that both (AA and $\mathrm{PNH}$ are rare disorders this association cannot be a chance finding $(16,37)$. AA results at least in some situation from an immune-mediated attack against the hematopoietic stem cell (76). In order to develop PNH a patient must have both a PIG-A mutation and an underlying aplastic process. BMF is clinically obvious in patients who initially present with AA and then develop PNH. In patients who initially present with PNH, BMF may not be obvious, because by the time of diagnosis the PNH clone has expanded to the point when it represent a substantial proportion of the patient's hematopoiesis. The existence of a florid PNH clone while the rest of hematopoiesis is depressed suggests that the PNH clone should be saved from the damage to the remaining bone marrow, most likely autoimmune in origin. One possible explanation lies in the suggestion that some missing GPI-anchored proteins may be critical target recognized by immune effector cells. PNH clones would survive because they are selectively resistant to the autoimmune assault that eliminated most normal clones $(15,16,39)$. Thus we can summarize that the damage (autoimmune in character?) to stem cells causing bone marrow failure is mediated through a GPI-linked surface molecules. In this case the PNH cells lacking these molecules will survive. According to this conception PNH clones do not play a causative role. This suggestion has recently received support from the finding that PNH microclones were detected in normal people $(1,54)$. Existence of small clones with PIG-A mutations in normal individuals, shows clearly that PIG-A gene mutations are not sufficient for development of $\mathrm{PNH}$ and that a second factor is required to explain the pathogenesis of PNH. In favor of this statement are also recent experimental works concerned with detailed investigations how inactivating mutation of the PIG-A gene affect hematopoiesis $(45,68)$. Which mechanism may be responsible for the suppression of hematopoiesis in PNH. Horikawa et al. (26) detected reduced susceptibility of blood cells from patients with PNH to apoptosis relative to those from healthy individuals. It is thus conceivable that apoptosis also operate to cause BM hypoplasia in $\mathrm{PNH}$.

\section{PNH and thrombosis}

Thrombotic complications are particularly prominent and severe in PNH and account for about $50 \%$ of all deaths in patients with PNH (8). Fatal thrombosis was found in 3 of our 8 patients (28). Thromboses with fatal outcome are very common in the portal system or in the brain. One of our patients died of left transverse sinus thrombosis. Severe headaches may occur in some patients without any objectively demonstrable neurologic abnormalities. This complications may be due to small venous occlusions. Recurrent attacks of abdominal pain are common. The possibility that a thrombosis in the portal or mesenteric veins is the cause of the pain must always be taken in consideration (14). Severe abdominal pain dominated the clinical feature of one of our patients. The patient died of stercoral peritonitis after an operation for infarction of the small intestine. Multiple thromboses of the intrahepatic branches of the portal vein and thrombosis of the lienal vein were found at autopsy (28). Hepatic venous thrombosis (Budd-Chiari syndrome) is a serious complication and in various series 15 to $30 \%$ of patients developed thrombosis in this location (33). It may also develop in a subclinical form detectable by ultasonography (6). Thromboses in other locations may also develop (27). The etiology of the thrombophilia associated with PNH is obscure. The relationship between thrombosis and PIG-A deficiency has been suggested $(53,74)$ but not fully clarified. It has been also ascribed to the intravascular 
release of ADP from red cells leading to platelet aggregation.

\section{Clinical feature, course of the disease and spontaneous recovery}

The natural course of PNH is that of a chronic hemolytic anemia with the passage of red or dark urine in the morning. The hemoglobinuria occurs during sleep regardless of the time of day (28). It usually begins insidiously. In some patients spontaneous hemoglobinuria occur when the number of abnormal red cells will reach certain level. Attacks of hemoglobinuria may be also initiated by infections and other causes, especially blood transfusions (in details see 27). It is imperative to use on-line white cell filters for all transfusions. The previously reported instances of hemoglobinuria triggered by blood transfusions resulted in fact from white cell reactions activating complement (37). In patients with repeated hemoglobinurias and permanent hemosiderinuria iron deficiency may develop. There exists two-way relationship of PNH to AA. On one hand there are patients who originally present with fully developed hemolytic process with hemoglobinuria representing florid PNH. These patients may gradually develop pancytopenia with hypoplastic and eventually an aplastic bone marrow. Luzzatto refers to this situation as spent PNH (37). On the other hand there are patients presenting originally with aplastic anemia who develop later on clinical and laboratory feature of $\mathrm{PNH}$. This development was observed to take place in up $80 \%$ of patients treated with anti-lymphocyte globulin (69) but it may occur in patients treated otherwise.

The disease has a chronic but unfavorable course. The mean survival time in 22 patients of Marks (41) was 6,6 years since the onset of the disease. In a recent study of 80 patients who were followed for up to 48 years, the median acturial survival was 10 years, with $28 \%$ of patients surviving for 25 years. Patients for whom the cause of death was known died either from venous thrombosis or hemorrhage mainly due to thrombocytopenia (24). But spontaneous recovery are possible. Of the 35 patients of Hillmen et al. (24) who survived for 10 years or more 12 had a spontaneous recovery. No PNH-affected cells were found among the erythrocytes or neutrophils of the patients in prolonged remission, but a few PNH-affected lymphocytes were detectable in three of the four patients tested. One other patient died from bleeding due to severe thrombocytopenia 37 years after the diagnosis of PNH and et least 8 years after Ham's test has become negative (24). We have reported two patients with spontaneous long-term recovery (30). In the first patient with typical PNH picture at presentation, the normal clinical, and laboratory findings and negative Ham's test are now present for 17 years, including normal results of CD 59 in erythrocytes and neutrophils tested in the last year. In the second patient with severe pancytopenia and bone marrow hypoplasia at presentation which necessitated 196 blood transfusions, the duration of remission is non
38 years. The only abnormal finding is moderate thrombocytopenia without hemorrhagic manifestations.

The PNH clone has a long but probably finite life span. If by the time the PNH clone is exhausted, BMF has not recovered, the patient developed clinically from $\mathrm{PNH}$ to AA. If by the time the PNH clone is exhausted, BMF has recovered, the patient evolves to "cured“ $\mathrm{PNH}$ (37). The cure from $\mathrm{PNH}$ is not necessarily associated with the complete cure from BMF, at least in the patient of Hillman et al. (24) and in one of our patients the thrombocytopenia persisted. It would be interesting to see what happened in these cases with PIG-A gene if very sensitive methods of detection, such as PC, would be used.

\section{The diagnosis of PNH}

The diagnosis of PNH is made by one or more tests that assess the susceptibility of the patient's cell to lysis by human complement: the acidified serum lysis test (Ham test 19), the complement lysis sensitivity test (CLS test - Rosse and Dacie - 56) and the sucrose lysis test „sugar water test (Hartman - 21). This test has been used extensively as a simpler version of the Ham test. Unfortunately it can give both false positive and false negative results and is not considered as very helpful by Luzzatto (37).

Flow cytometry of erythrocytes using anti-CD 59 or granulocytes using either anti-CD 55 or anti-CD 59 provides more accurate technique for the diagnosis of $\mathrm{PNH}$; it is clearly more specific, more quantitative and more sensitive than the tests that depend upon hemolysis by complement (63). By flow cytometry it is possible to identify GPI-anchor deficient populations that comprise more than $1 \%$ of the red cells (18). Even more sensitive was found to be an extremely sensitive mutation specific PCR-based analysis in the mononuclear cells (54).

But it now seems clear that we must make distinction between the detection of very occasional PNH cells in patients with BMF and PNH as a clinicohematological entity. High sensitivity of flow cytometry and/or PCR methods is able to reveal patients who have small PNH clones - usually at some stage of the course of aplastic anemia. It seems that patients with very small PNH clones are unlikely to experience signs and symptoms of intravascular hemolysis and therefore it might be unjustified to refer to them as having PNH. However we do not know what is the minimum size for a PNH to produce clinical symptoms and signs (38).

\section{PNH, Myelodysplasia, and Acute Leukemia}

The relationship of PNH to AML and MDS was analyzed in details by Harris et al. (21). They collected 119 cases that are well-documented. In this series 104 myeloid dyscrasias involving several categories in addition to AML (AMoL, AMegL, EL, RAEB, RARS, CML a CMMoL), as well as 15 lymphoid dyscrasias are described. In 32 of the patients with hematological dyscrasias where karyotypes 
were analyzed, 7 were found to be normal and 25 were found to harbour various alternation. In 5 of 7 instances evidence indicates that the dyscratic cell arises from the PNH clone. The prevalence of non-myelocytic leukemia or lymphoma can be considered as coincidental association of the two disorders. The key question regarding AML development in PNH has been whether the abnormal environment of PNH marrow predispose leukemogenesis or whether AML blasts evolve directly from PNH cells themselves. In studies of PNH patients that have been performed to resolve this issue, available evidence favours the proposal that leukemic blasts in fact arise from PNH clones, rather then sui generis. In a 1993 series of PNH patients, Nakahata et al. (46) found that $90 \%$ of AM leukemic blasts were CD 59and $25 \%$ DAF. In AML blasts of another PNH patient, Shichishima et al. (62) found that CD 59 was absent and DAF content was below normal. Stafford et al. (65) established that the blast cells from a PNH patient who after 10 years developed AML harboured two closely-spaced point mutations in exon 4 of the PIG-A gene providing direct evidence that the leukemic clones arise presumably as a result of a second mutation. Dunn et al. (16) reported GPI-anchored protein-deficient cells in 9 of 39 (23\%) patients with myelodysplasia. The presence of PNH population was strongly correlated with hematologic improvement after administration of antithymocyte globulin (16).

\section{Therapy}

Treatment of PNH consists mainly of supportive measures such as transfusions, antibiotics and anticoagulant therapy in indicated conditions. Suitable patients may be cured by marrow transplantation.

Transfusions are often necessary in patients with florid PNH and a severe anemia. Washed erythrocytes are usually recommended to remove complement contained in plasma. It is advisable to use on-line white cell filters for all transfusions to abolish white cell reactions activating complement (37). Use of prophylactic anticoagulants in PNH has been recommended but a clear-cut evidence of a beneficial effect of prophylactic anticoagulation is lacking. Antifibrinolytic therapy was considered to be safe and effective in the management of PNH thrombotic complications such as Budd-Chiari syndrome, in portal and mesenteric veins thromboses (42).

Bone marrow transplantation is an effective, albeit high risk method for treatment of $\mathrm{PNH}(3,31,61)$. The evaluation of the outcome of 57 consecutive allogeneic bone marrow transplantations for PNH reported to the International Bone Marrow Transplant Registry between 1948 and 1995 has shown the 2-year probability of survival in 48 recipient of HLA-identical sibling transplants to be $56 \%$. Two recipient of identical twin transplants remain alive 8 and 12 years after treatment. The most common causes of treatment failure were graft failure and infections (61). The decision to do a transplant requires weighing a patient's prognosis with non transplant therapy taking in consideration that 10-20\% of patients may undergo spontaneous remissions after a protracted course (24).

\section{References}

1. Araten DJ, Nafa K, Pakde Suwan K et al. Clonal populations of hematopoietic cells with paroxysmal hemoglobinuria genotype and phenotype are present in normal individuals. Proc Natl Acad Sci U.S.A. 1999;96:5209-14

2. Armstrong $\mathrm{C}$, Schubert J, Veda et al. Affected paroxysmal nocturnal haemoglobinuria $\mathrm{T}$ lymphocytes harbour a common defect in assembly of N-acetyl-D-glucosamine inositol phospholipid corresponding to that in class A thy-1-murine lymphoma mutants. J Biol Chem 1991;267:25347-51.

3. Bemba M, Guardiola P, Garderet L. Bone marrow transplantation for paroxysmal nocturnal haemoglobinuria. Br J Haematol 1999;105:366-8.

4. Bessler M, Fehr J. fc(III receptors) (FcR III) on granulocytes: a new specific and sensitivity test for paroxysmal nocturnal haemoglobinuria. Eur J Haematol 1991;47:179-82

5. Bessler M, Mason GJ, Hillmen $P$ et al. Somatic mutations and cellular selection in paroxysmal nocturnal hemoglobinuria. Lancet 1994;343:951-3.

6. Birgens HS, Hancke S, Rosenklint A et al. Ultrasonic demonstration of clinical and subclinical hepatic venous thrombosis in paroxysmal nocturnal haemoglobinuria. Br J Haematol 1986;64:737-43.

7. Brodsky RA, Vala MS, Barber JP et al. Resistance to apoptosis caused by PIGA gene mutation in paroxysmal nocturnal hemoglobinuria. Proc Natl Acad Sci U.S.A. 1997:94:8756-60.

8. Crosby WH. Paroxysmal nocturnal hemoglobinuria: relation of the clinical manifestations to underlying pathogenic mechanisms. Blood 1953;8:769-812.

9. Dacie JV, Gilpin A. Refractory anaemia (Fanconi type). Arch Dis Child 1944; 19:155-62

10. Dacie JV, Israels MCG, Wilkinson JF. Paroxysmal nocturnal hemoglobinuria of the Marchiafave type. Lancet 1938;1:479-91.

11. Dacie JV, Lewis SM. Paroxysmal nocturnal hemoglobinuria: variation in clinical severity and association with bone-marrow hypoplasia. Br J. Haematol 1961:7:442-57.

12. Dacie JV, Mollison PL. Survival of transfused erythrocytes from a donor with nocturnal haemoglobinuria. Lancet 1949;1:390-2.

13. De Sandre G, Gihotto G, Mastella G. L'aceticolinesterase eritrocitaria. II. Rapporti con le malatie emolitiche. Acta Med Patav 1956;16:310-35.

14. Dunkas MA, Di Lorenzo PE, Mohler DN. Intestinal infarction caused by paroxysmal nocturnal hemoglobinuria. Am J Hematol 1987;16:75-7.

15. Dunn DE, Nagakura S, Tanawattana-Charoen P et al. The PNH phenotype (GPIanchored protein-deficiency) protects hematopoietic target against lymphotoxic attack (Abstract). Blood 1997;90(suppl 1):407a.

16. Dunn DE, Tanawattana-Charoen P, Boccuni $P$ et al. Paroxysmal nocturnal hemoglobinuria cells in patients with bone marrow failure syndromes. Ann Intern Med 1999;131:401-408.

17. Enneking J. Eine neue Form intermitierender Hämoglobinurie (hemoglobinuria paroxysmalis nocturna). Klin Wschr 1928:7:2045-7.

18. Hall SE, Rosse WF. The use of monoclonal antibodies and flow cytometry in the diagnosis of paroxysmal nocturnal hemoglobinuria. Blood 1996;87:5332-40.

19. Ham TH. Chronic hemolytic anemia with paroxysmal nocturnal hemoglobinuria Study of the mechanism of hemolysis in relation to acid-base equilibrium. New Engl J Med 1937;217:915-7.

20. Ham TH, Dingle JH. Studies on destruction of red cells. II. chronic hemolytic anemia with paroxysmal nocturnal hemoglobinuria: certain immunological aspects of the hemolytic mechanism with special reference to serum complement. J Clin Invest 1939;18:657-73.

21. Hartman RC, Jenkins DE, Arnold AB. Diagnostic specificity of the sucrose hemolysis test for paroxysmal nocturnal hemoglobinuria. Blood 1970;35:462-75..

22. Harris JW, Koscick R, Lazarus HM et al. Leukemia arising out of paroxysmal nocturnal hemoglobinuria. Leukemia Lymph. 1999;32:401-26.

23. Hillmen P, Bessler M, Mason PJ et al. Specific defect in N-acetylglucosamine incorporation in the biosynthesis of the glycosylphosphatidylinositol anchor in cloned cell lines from patients with paroxysmal nocturnal hemoglobinuria. Proc Natl Acad Sci U.S.A. 1993;90:5272-76.

24. Hillmen P, Lewis PM, Bessler $M$ et al. Natural history of paroxysmal nocturnal hemoglobinuria. N Engl J Med 1995;333:1253-58.

25. Holguin MH, Frederick LR, Bernshaw NY et al. Isolation and characterization of a membrane protein from normal human erythrocytes that inhibits reactive lysis of the erythrocytes of paroxysmal nocturnal hemoglobinuria. J Clin Invest 1989;84:7-17

26. Horikawa K, Nakakuma H, Kawaguchi T. Apoptosis resistance of blood cells from patients with paroxysmal nocturnal hemoglobinuria, aplastic anemia, and myelodysplastic syndrome. Blood 1997;90:2716-22.

27. Chrobák L, Brabec V. Paroxysmální noční hemoglobinurie. Thomayerova sbírka, SZN Praha 1965. 102 pp. 
28. Chrobák L, Brabec V, Wiedermann B. et al. Paroxysmale nächliche Hämoglobinurie. Bericht über 8 Fälle unter besonderer Berücksichtigung von Panzytopenie und Knochenmarkaplasie. Folia haemat (Lpz) 1964;82:256-293

29. Chrobák L, Groh J. Paroxysmální noční hemoglobinurie. Sborník věd. prací VLA J. Ev. P. 1957;5:135-155

30. Chrobák L, Toušková M, Žák P et al. Paroxysmální noční hemoglobinurie (patogeneze a vztah $\mathrm{k}$ dřeňové aplazii). Hematol. Transfusiol. 2000; v tisku

31. Kawahara K, Witherspoon RP, Storb R. Marrow transplantation for paroxysma nocturnal hemoglobinuria. Am J. Hematol 1992;39:283-8.

32. Kolanus HJ, Schmidt RE. The PIG-anchoring defect in NK lymphocytes of PNH patients. Blood 1990;76:1181-7.

33. Leibowitz AI, Hertmann RC. Annotation: The Budd-Chiari syndrome and paroxysmal nocturnal haemoglobinuria. Br J Haematol 1981;48:1-6.

34. Letman H. Possible paroxysmal nocturnal hemoglobinuria with pronounced pancytopenia, reticulocytopenia, and without hemoglobinuria simulating aplastic anemia. Blood 1952; 7:842-49.

35. Lewis SM, Dacie JV. Neutrophil (leukocyte) alkaline phosphatase in paroxysmal nocturnal hemoglobinuria. Br J Haematol 1965;11:549-56.

36. Lewis SM, Szur L, Dacie JV. The pattern of erythrocyte destruction in haemolytic anaemia as studied with radioactive chromium. Br J Haematol 1960;6:122-39.

37. Luzzatto L. Paroxysmal nocturnal haemoglobinuria. Haematology 1996; Panache Design Singapore, p. 120-7.

38. Luzzatto L, Bessler M. The dual pathogenesis of paroxysmal nocturnal hemoglobinuria. Current Opinion Hematol 1996;3:101-3.

39. Luzzatto L, Bessler M, Rotoli B. Somatic mutation in paroxysmal nocturnal hemoglobinuria: A blessing in disguise? Cell 1997;80:1-4

40. Marchiafava E. Anemia emolitica con emosiderinuria perpetua. Policlinico, Sez Med 1928;35:105-17

41. Marks J. The Marchiafava-Micheli syndrome (Paroxysmal nocturnal haemoglobinuria). Quart J Med 1949;18:105-21.

42. Mc Mullin MF, Hillmen P, Jackson J et al. Tissue plasminogen activator for hepatic vein thrombosis in paroxysmal nocturnal haemoglobinuria. J Intern Med 1994;235:85-9

43. Meri S, Morgan BP, Davies A et al. Human protectin (CD 59), an 18.000-20.000 MW complement lysis restricting factor, inhibits $\mathrm{C} 5 \mathrm{~b}-8$ catalysed insertion of $\mathrm{C} 9$ into lipid bilayers. Immunulogy 1990; 7:1-9.

44. Miyata T, Takeda J, Iida Y et al. The cloning of PIG-A, a component in the early step of GPI-achor biosynthesis. Science 1993;259:1318-20.

45. Murakami Y, Kinoshita T, Maeda Y. et al. Different roles of glycosylphosphatidylinositol in various hematopoietic cells as revealed by a mouse model of paroxysmal nocturnal hemoglobinuria. Blood 1999;94:2963-70.

46. Nakahata JI, Takahashi M, Fuse I et al. Paroxysmal nocturnal hemoglobinuria with myelofibrosis: progression to acute myeloblastic leukemia. Leukemia Lymph 1993:92:137-42.

47. Nafa K, Bessler M, Castro-Malaspina $\mathrm{H}$ et al. The spectrum of somatic mutation in the PIG-A gene in paroxysmal nocturnal hemoglobinuria includes large deletions and small duplications. Blood Cells Mol Dis 1998;24:370-84.

48. Nafa K, Mason PJ, Hillman P et al. Mutations in the PIG-A gene causing Paroxysmal Nocturnal Hemoglobinuria are mainly of the frameshift type. Blood 1995;86:4650-5

49. Nakakuma H, Nagakura S, Horikawa K et al. Interleukin-2-dependent T-cell lines established from paroxysmal nocturnal hemoglobinuria patients. Blood 1994;84:309-14.

50. Nakakuma $\mathrm{H}$, Nagakura $\mathrm{S}$, Iwamoto $\mathrm{N}$ et al. Paroxysmal nocturnal hemoglobinuria clone in bone marrow of patients with pancytopenia. Blood 1995;85:1371-6.

51. Nicholson-Weller A, March JP, Rosenfeld SJ et al. Affected erythrocytes of patients with paroxysmal nocturnal hemoglobinuria are deficient in the complement regulatory protein, decay accelerating factor. Proc Natl Acad Sci U.S.A. 1983;80:5430-3

52. One SB, Osunkoya BO, Luzzatto L. Paroxysmal nocturnal hemoglobinuria: evidence for monoclonal origin of abnormal red cells. Blood 1970;36:145-52.

53. Plongh M, Plesner T, Roune E et al. The receptor for urokinase-type plasminogen activator is deficient on peripheral blood leukocytes in patients with paroxysmal nocturnal hemoglobinuria. Blood 1992;79:1447-55.

54. Rawstron AC, Rollinson SJ, Richards S. The PNH phenotype cells that emerge in most patients after CAMPATH-1H therapy are present prior to treatment. $\mathrm{Br}$ J Haematol 1999; 107:148-53.
55. Rosse WF. Phosphatidylinositol-linked proteins and paroxysmal nocturnal hemoglobinuria. Blood 1990;75:1595-1601.

56. Rosse WJ, Dacie JV. Immune lysis of normal human and paroxysmal nocturnal haemoglobinuria (PNH) red blood cells: I. The sensitivity of PNH red cells to lysis by complement and specific antibody. J Clin Invest 1966;45:736-48.

57. Rosse WF, Ware RE. The molecular basis of paroxysmal nocturnal hemoglobinuria. Blood 1995;86:3277-86

58. Rotoli B, Bessler M, Afinito F, del Vecchio L. Membrane proteins in paroxysmal nocturnal haemoglobinuria. Blood Reviews 1993;7:75.

59. Rotoli B, Luzzatto L. Paroxysmal nocturnal hemoglobinuria. Semin. Hematol 1989;26:201.

60. Rotoli B, Robledo R, Scarpato N et al. Two populations of erythroid cell progenitors in paroxysmal nocturnal haemoglobinuria. Blood 1984;64:847-51.

61. Sašo R, Marsh J, Čevreska L et al. Bone marrow transplants for paroxysmal nocturnal hemoglobinuria. Br J Haematol 1999;104:392-6.

62. Shichishima T, Terasawa T, Hashimoto $\mathrm{C}$ et al. Discordant and hetorogenous expression of GPI-anchored membrane proteins on leukemic cells in a patient with paroxysmal nocturnal hemoglobinuria. Blood 1993;81:1855-62

63. Shichishima T, Terasawa T, Saitoh Y et al. Diagnosis of paroxysmal nocturnal haemoglobinuria by phenotypic analysis of erythrocytes using two-colour cytometry with monoclonal antibodies to DAF and CD 59/MACIF. Br J Haematol 1993; 85:378-86.

64. Schubert J, Uchiechowski P, Delany P et al. The PIG-anchoring defect in NK lymphocytes of PNH patients. Blood 1990;76:1181-7.

65. Stafford AA, Nagarajan S, Weinberg JB et al. PIG-A, DAF and protooncogene expression in paroxysmal nocturnal haemoglobinuria - associated acute myelogenous leukaemia blasts. Br J Haematol 1995;89:72-8

66. Strübing P. Paroxysmale Hämoglobinurie. Dtsch Med Wschr 1882;8:1-3.

67. Takeda J, Miyata T, Kawagoe K et al. Deficiency of the PIG-A gene in paroxysmal nocturnal haemoglobinuria. Cell 1993;73:703-11.

68. Tremml G, Dominguez C, Rosti V et al. Increased sensitivity to complement and decreased red blood cell life span in mice mosaic for a non-functional Piga gene. Blood 1999;94:2945-54

69. Tichelli A, Gratwohl A, Nissen C et al. Late haematological complications in severe aplastic anaemia. Br J Haematol 1988;69:413-18.

70. Toušek M. Paroxysmale Nachthämoglobinurie. Folia haemat (Lpz) 1955;73:284 300 .

71. Van den Bergh HAA. Ictère hémolytigue avec crises hémoglobinurigues. Fragilité globulaire. Rev Méd 1911;31:63-9.

72. Van der Schoot CE, Huizinga TW, Van't Veer-Korthof ET et al. Deficiency of glycosyl-phosphatidyl-inositol-linked membrane proteins of leukocytes in paroxysmal nocturnal hemoglobinuria. Description of a new diagnostic cytofluorometric assay. Blood 1990;76:1853-9.

73. Voswinckel P. Der schwarze Urine Berlin, Germany Blackwell, 1993. Panache Design Singapore, p. 120-7.

74. Wiedmer T, Hall SE, Ortel TL et al. Complement induced vesiculation and exposure of membrane prothrombinase sites in platelets of paroxysmal nocturnal hemoglobinuria. Blood 1993;82:1192-6.

75. Yamashina M, Ueda E, Kinoshita T et al. Inherited complete deficiency of 20-kilodalton homologous restriction factor (CD 59) as a cause of paroxysmal nocturnal hemoglobinuria. N Engl J Med 1990;323:1184-1189.

76. Young NS, Barret AJ. The treatment of acquired aplastic anemia. Blood 1995;85:3367-77.

Submitted February 2000.

Accepted March 2000.

Prof. MUDr. Ladislav Chrobák, CSc.,
University Teaching Hospital,
Department of Clinical Hematology,
50005 Hradec Králové,
Czech Republic. 